\title{
Construção de um Guia para o uso do Instagram no contexto do ensino remoto: empatia durante a pandemia da COVID-19
}

\author{
Amanda C D Tavares ${ }^{1}$, Ednny K A Sales ${ }^{1}$, Ely T S Ramos ${ }^{1}$, Israel D S Júnior ${ }^{1}$, \\ Ivone M Oliveira ${ }^{1}$, Maria C M Silva ${ }^{1}$, Patricia R V V Andrade ${ }^{1}$, Soraya R S Medeiros ${ }^{1}$ \\ ${ }^{1}$ Instituto Metrópole Digital (IMD) \\ Universidade Federal do Rio Grande do Norte - Natal, RN - Brasil \\ amandacdt@ufrn.edu.br, ednnysales@gmail.com, elyticiana@gmail.com \\ israndsantos@gmail.com, ivone65@gmail.com, medeiros.mc@hotmail.com, \\ patricia@nei.ufrn.br, soraya_rb@ufrn.edu.br
}

\begin{abstract}
Resumo. A pandemia de Covid-19 trouxe um desafio para a educação: estabelecer uma rede educacional eficaz virtualmente. Na perspectiva de cativar discentes com inovações, desenvolvemos, em uma disciplina do Mestrado, um material sobre o Uso do Instagram no ensino remoto para professores do $5^{\circ}$ ano do Ensino Fundamental (EF) na área de Linguagens. Este artigo apresenta uma proposta de interação professor/aluno no Instagram, propondo habilidades descritas na Base Nacional Comum Curricular (BNCC) [Brasil 2018] com diversidade de gêneros textuais e ferramentas que a rede social possibilita. Assim, sugerimos sequências didáticas com cinco atividades norteadoras que descrevem como aplicar os gêneros por meio da rede social, que foram compiladas para o guia e tal material foi divulgado buscando atingir o maior número de professores possivel.
\end{abstract}

\begin{abstract}
The Covid-19 pandemic brought a challenge to educators: establishing an effective remote educational network. Seeking to involve students in an innovative didactic method, we developed a guide for Using Instagram in remote education. The guide was developed as part of a University's Master's program, focusing on using remote teaching in the context of K-12 Portuguese classes. This paper proposes an Instagram-mediated student/teacher interaction, including abilities mentioned in the Brazilian Nacional Core Curriculum and combining a variety of genres and tools that Instagram offers, which can be used in an educational way. We also suggest a didactic sequence including five activities that describe how the teacher can work with various genres using the social media tool. The guide was developed aiming to reach as many educators as possible.
\end{abstract}

\section{Introdução}

O contexto da pandemia da Covid-19 [World Health Organization et al. 2020] criou a necessidade de se estabelecer outros cenários para que o processo de ensino e aprendizagem continuasse sendo viabilizado. Diante disso, observamos que as redes sociais ganharam bastante espaço, sendo reconhecidas como um ambiente de interação entre escolas, alunos, docentes e comunidade em geral, visto que permitem a difusão do conhecimento em larga escala a qualquer momento do dia sem que as pessoas precisem estar em um 
mesmo ambiente. Assim, elas também evidenciam o protagonismo do aluno em poder discutir temáticas do seu interesse e cotidiano, bem como configuram-se como ambientes colaborativos [Faria and Silva 2012].

Entretanto, para que a aprendizagem colaborativa por meio das redes sociais se efetive, é necessário que o docente possua Letramento Computacional [DiSessa 2001], bem como desenvolva Competências Digitais [Council 2006]. Além disso, é salutar que existam recursos que permitam que o professor adquira esses saberes a fim de que sua aula seja fluida e a interação constante. Ciente dessas necessidades, um grupo de professores se reuniu com o propósito de elaborar materiais para colegas de profissão, tendo em mente essas necessidades.

Nesse sentido, o presente estudo tem como objetivo apresentar a construção de um Guia para o uso do Instagram no ensino remoto. Para tanto, o público-alvo escolhido foi professores do $5^{\circ}$ ano do Ensino Fundamental que atuam com a área de Linguagens através do componente curricular Língua Portuguesa. Para realizar a organização das etapas do Guia, foram consultadas a Base Nacional Comum Curricular (BNCC) [Brasil 2018] e Currículo de Referência em Tecnologia e Computação do Centro de Inovação para a Educação Brasileira (CIEB) [CIEB 2020]. A linguagem utilizada no material é instrucional. Além desta Introdução, o artigo encontra-se dividido em cinco seções: a seção "Fundamentação teórica" discute sobre educação na era digital; as redes sociais como recurso pedagógico, além da relação do guia com o modelo Conhecimento Tecnológico Pedagógico do Conteúdo (CTPC). Na seção "Trabalhos relacionados", são elencados dois materiais relacionados ao guia proposto; na "Metodologia", encontram-se as etapas de desenvolvimento da proposta, iniciadas com questionamentos, que conduziram a quatro fases de produção; os "Resultados e discussões" apresentam resumidamente as cinco propostas pedagógicas e demonstram o material produzido através de imagens; as "Considerações finais" enfatizam a necessidade de uma prática inovadora; destacando o potencial das redes sociais no processo de ensino-aprendizagem e, ainda, trazendo reflexões acerca daquilo que se tem feito e do que se pode fazer.

\section{Fundamentação Teórica}

Educar no contexto atual da pandemia da Covid-19 exige adaptabilidade sobre o modo de pensar, aprender a aprender e aprender a fazer [Dellors et al. 1999]. Desse modo, faz-se necessário refletir, quanto professor, sobre o posicionamento diante dos desafios postos pelas redes sociais, que fazem parte da vida dos discentes, nativos digitais, dentro e fora dos muros da escola. Como agir? O que fazer? De que maneira esses recursos podem ser aproveitados? Há, portanto, uma necessidade de produzir material que atenda a essa demanda. O mundo virtual, por meio das redes sociais, sites e aplicativos permite estabelecer vínculos entre pessoas, comunidades e empresas, tendo como característica principal o compartilhamento de informações e a interação. Conforme Bates [Bates 2016, p. 54-56], o conhecimento envolve o conteúdo e habilidades. A cultura digital trouxe a necessidade de um ensino que contemple o conteúdo, mas também, o desenvolvimento de habilidades que atendam às demandas das práticas sociais relacionadas ao mundo tecnológico: habilidade de comunicação; autoaprendizagem; ética e responsabilidade; colaboração e flexibilidade; competências digitais; gestão do pensamento e do conhecimento.

De acordo com o CIEB [CIEB 2020], Estratégias de Aprendizagem Remota 
(EAR) são medidas emergenciais que foram pensadas e organizadas para que ocorra a educação em contexto de pandemia mundial objetivando garantir o ensino não-presencial, principalmente por meio das Tecnologias Digitais da Informação e Comunicação (TDIC). Nas EAR o ensino ocorre totalmente em isolamento físico e pode ocorrer de forma síncrona, com professores e alunos interagindo ao mesmo tempo ou assíncrona, com atividades orientadas previamente para serem realizadas em momentos futuros.

No contexto de isolamento físico imposto ao setor educacional a didática de EAR adotada para a continuidade do processo de ensino e aprendizagem precisou ser repensada e adaptada. A didática pode ser entendida como o campo de estudo que trata dos objetivos, condições e meios de realização do processo de ensino, o que envolve também aspectos extrínsecos ao processo educativo [Libâneo 2002]. Dessa forma, para proporcionar continuidade nas trocas educacionais, professores precisaram analisar inúmeros aspectos para que o processo seja o mais includente possível, tendo em vista que estudantes das mais variadas classes sociais e condições econômicas encontram-se diante do desafio de manutenção dos estudos em suas casas. É preciso considerar o domínio das funções e acesso às TDIC do próprio professor e dos discentes, bem como conectividade à internet; equipamentos; adaptação das metodologias presenciais para a remota.

O material didático a ser utilizado no contexto de EAR também precisou ser revisado. Ele é, em sua maioria, digitalizado e multimodal; entretanto, de acordo com a necessidade do docente e dos estudantes pode ser feito uso de material impresso. Os professores podem selecionar o material que mais se adeque a seus objetivos de aula remota. É possível analisar e escolher entre transmissões de aulas pela televisão; vídeo aulas gravadas e disponibilizadas em redes sociais; aulas síncronas e online transmitidas por redes sociais; compartilhamento de conteúdos digitais em ferramentas online e envio de material impresso com conteúdo educacional.

A opção pelo trabalho com redes sociais se deu por considerar a vantagem de que elas favorecem o trabalho com hipertextos, pelas fáceis conexões a outros textos ao mesmo tempo, nas mais variadas formas de representação da linguagem, na integração de textos escritos, imagens, vídeos, gêneros diversos; tudo podendo ser acessado através de links; elas também garantem a autonomia do aluno na construção do conhecimento; estimulam o interesse pelos estudos. A tecnologia torna-se, então, um recurso contributivo para o alcance dos objetivos propostos, enquanto torna-se também objeto de letramento digital do estudante. De acordo com Morais et al [Morais et al. 2018, p. 908], o aplicativo Instagram oferece variados instrumentos de interação: postagens, curtidas, comentários, publicações ao vivo, stories (compartilhamentos de momentos específicos). A pesquisa constata a sua funcionalidade como ferramenta educacional, a versatilidade da produção criativa voltada à comunicação, além do potencial de trabalho com diferentes discursos e gêneros textuais.

A literatura demonstra que há educadores incorporando o uso do Instagram em suas práticas educacionais. Porém, a implementação ocasional de tais práticas não necessariamente implica na existência de um modelo de aplicação da ferramenta, o que pode ser justificado pelo fato de o Instagram ser uma ferramenta recente. Portanto, para que haja sucesso no uso da ferramenta, é necessário que haja uma estreita articulação entre planejamento e execução das atividades, bem como um enfoque na intencionalidade pedagógica do uso da ferramenta [Pereira et al. 2019]. 
Segundo Rolando et al. [Rolando et al. 2015, p. 177], um dos mais significativos referenciais teóricos para pesquisa a respeito de práticas pedagógicas integradas ao uso de tecnologias é chamado de Conhecimento Tecnológico Pedagógico do Conteúdo (CTPC), TPACK em inglês, que consiste num modelo proposto por Shulman [Shulman 1987] e ampliado por Mishra e Khoeler [Mishra and Koehler 2006], tendo três eixos como base: o tecnológico, o pedagógico e o conteúdo. A interseção entre eles traz novos conceitos e descreve os tipos de conhecimento que devem fundamentar as práticas educacionais docentes que utilizam ferramentas tecnológicas. É possível estabelecer uma relação entre o Technological Pedagogical Content Knowledge (TPACK) com as propostas do guia, considerando que a utilização do Instagram, como uma tecnologia educacional, traz uma combinação entre diversos conhecimentos, diversas situações e diversos conceitos, a partir de ações diversificadas. Também oferece um conjunto de conhecimentos que embasam as práticas pedagógicas e que utilizam-se de ferramentas tecnológicas. Quanto às ações metodológicas, traz perguntas investigativas, estabelece procedimentos de pesquisa e análise dos documentos.

Existem diversas formas de linguagens utilizadas nos textos que podem ser formais ou informais, verbais ou não verbais. Assim, os gêneros discursivos são a forma como a linguagem se organiza para se manifestar nas diversas situações de comunicação. Os sujeitos utilizam os gêneros discursivos em práticas sociocomunicativas e culturais, desempenhando atividades interativas e dinâmicas, uma vez que sofrem modificações a partir do meio em que o sujeito está inserido e que estão sendo veiculadas. Os gêneros do discurso são tão imprescindíveis que, sem eles, a comunicação verbal seria quase que impossível [Bakthin 2011].

A importância do ensino por meio de gêneros discursivos está na sua fluidez para um trabalho interdisciplinar, além de apresentar a linguagem de maneira contextualizada, considerando sua função comunicativa, privilegiando aspectos socioculturais, conforme Marcuschi [Marcuschi 2009]. Outros aspectos que também lhes são inerentes: são dinâmicos; trazem um contexto sociohistórico; apresentam situações com fins específicos; estão relacionados a domínios discursivos; são recorrentes e revelam formatos mais ou menos definidos, sem contudo, serem inflexíveis, conforme aponta Marcuschi [Marcuschi 2009]. A partir dessas características, entende-se que o ensino realizado por meio de sua instrumentalidade favorece o letramento linguístico, contribuindo para o uso da linguagem de maneira efetiva.

Os gêneros textuais são instrumentos linguísticos que atendem às mais diversas necessidades comunicativas da sociedade, e é papel da escola ensinar o uso da língua em sociedade [Ribeiro 2009]. Sabendo disso, e ainda que o Instagram configura-se como uma excelente ferramenta capaz de possibilitar o ensino com diversos gêneros textuais junto aos estudantes do Ensino Fundamental, a julgar por sua interatividade e pela familiaridade do público estudantil, possibilitar um estudo pautado no ensino de gêneros textuais pode colaborar para aprendizagem da língua materna bem como possibilitar o aprimoramento da leitura, da produção textual e da oralidade e, consequentemente, contribuir para uma formação cidadã plena, capaz do sujeito se comunicar e intervir no mundo no qual está inserido. 
IX Congresso Brasileiro de Informática na Educação (CBIE 2020)

Anais do XXVI Workshop de Informática na Escola (WIE 2020)

\section{Trabalhos Relacionados}

O trabalho de Bastos e Boscariolli [Bastos and Boscarioli 2020] aborda um guia com reflexões sobre as macrocompetências digitais que o professor deverá atingir ao elaborar um plano para uma aula remota, com o objetivo de tornar a aula mais significativa tanto para o aluno quanto para o professor. Garcia et al. [Garcia et al. 2012] produziram um guia voltado para a formação docente no que diz respeito ao uso das tecnologias aplicadas ao ensino de Língua Estrangeira (LE), nos anos do Ensino Fundamental II e Ensino Médio. A proposta traz maneiras de se ensinar a LE a partir de abordagens comunicativas visando a promover experiências significativas e motivadoras de aprendizagem. Porém, este trabalho não está direcionado para o ensino remoto, ou seja, não leva em consideração o contexto da pandemia de Covid-19.

Santos et al. [Santos and Nunes 2019] foram além, e elaboraram um guia baseado nas atividades da dissertação de mestrado de Santos. O guia discute propostas de atividades desplugadas com objetivo de fornecer ideias para a realização de atividades destinadas ao desenvolvimento do Pensamento Computacional em disciplinas como: Língua Portuguesa, Matemática, Ciências e Tecnologias. Este trabalho se assemelha ao que propomos, pois discute a preocupação com o ensino-aprendizagem da Língua Portuguesa, no que diz respeito ao desenvolvimento da habilidade de expressão escrita.

Neste trabalho, a nossa preocupação é suprir a necessidade percebida de falta de propostas didáticas para o Ensino de Língua Portuguesa no ensino remoto, voltada para o desenvolvimento da habilidade (EF35LP15), em que além de trabalhar os gêneros textuais informativos, o professor possa trazer a temática da COVID-19 com o intuito de não só conscientizar os alunos, mas também levar a discussão além do ambiente escolar, utilizando a rede social Instagram como meio de divulgação principal dos projetos e atividades produzidos pelos alunos.

\section{Metodologia}

Para a construção do Guia, foram consideradas algumas questões, partindo das necessidades dos professores e alunos, e também de nossas vivências: QP1 - Como abordar diferentes tipos de gêneros textuais a partir do ensino remoto? QP2 - Como continuar interagindo com os alunos mesmo com o distanciamento? QP3 - Qual rede social se encaixa no perfil dos alunos na atualidade?

A partir de tais questionamentos o estudo foi dividido em 4 fases: i) definir público-alvo e referenciais teóricos para a produção; ii) desenvolver atividades que contemplassem gêneros textuais distintos; iii) criar um guia com as atividades sugeridas para uso no Instagram; iv) desenvolver um vídeo e site para integrar ao Guia. Para a primeira etapa, foram realizados estudos a partir de obras que abordavam práticas construcionistas com base na teoria de Papert [Papert 2007], buscando estratégias de aprendizagem remota que atendessem professores e alunos das redes públicas de ensino na continuidade das aulas, promovendo o ensino híbrido e ampliando as oportunidades de aprendizagem dos discentes, como sugere o CIEB [CIEB 2020]. Nesse sentido, na segunda etapa, buscamos desenvolver as atividades para a proposta de forma a apresentar aos professores maneiras de engajar os alunos em produções textuais, apesar do distanciamento social e organizá-las no Canva, o que nos levou a disponibilizar também um tutorial para uso do programa. 
$\mathrm{Na}$ terceira etapa, sentimos a necessidade de apresentar e armazenar o guia. Para isso, utilizamos o Google Sites, onde além do guia colocamos links tutoriais para playlists no YouTube que explicam como acessar, criar uma conta e utilizar as principais funcionalidades da rede social. Posteriormente, divulgamos os materiais por meio de um vídeo elaborado através do aplicativo Powtoon ${ }^{1}$, com referências ao momento de isolamento social, questionando os professores sobre sua interação com os alunos em meio a um momento de revolução tecnológica, sugerindo o uso do Instagram para promover aulas em diferentes perspectivas, por meio de uma linguagem atual.

Por fim, na quarta etapa, elaboramos um formulário utilizando o Google Forms para que os docentes que viessem a utilizar pudessem fornecer feedback referente à relevância e aplicabilidade do material.

\section{Resultados e Discussões}

O trabalho colaborativo propõe diversas possibilidades para o professor trabalhar variados gêneros textuais utilizando as redes sociais. Por exemplo, na proposta $1 \mathrm{o}$ aluno é levado a conhecer os conceitos do gênero textual cartaz: o que é, para que serve, qual sua função comunicativa. Por fim, é provocado a construir esse gênero textual colaborativamente versando sobre o tema Covid-19.

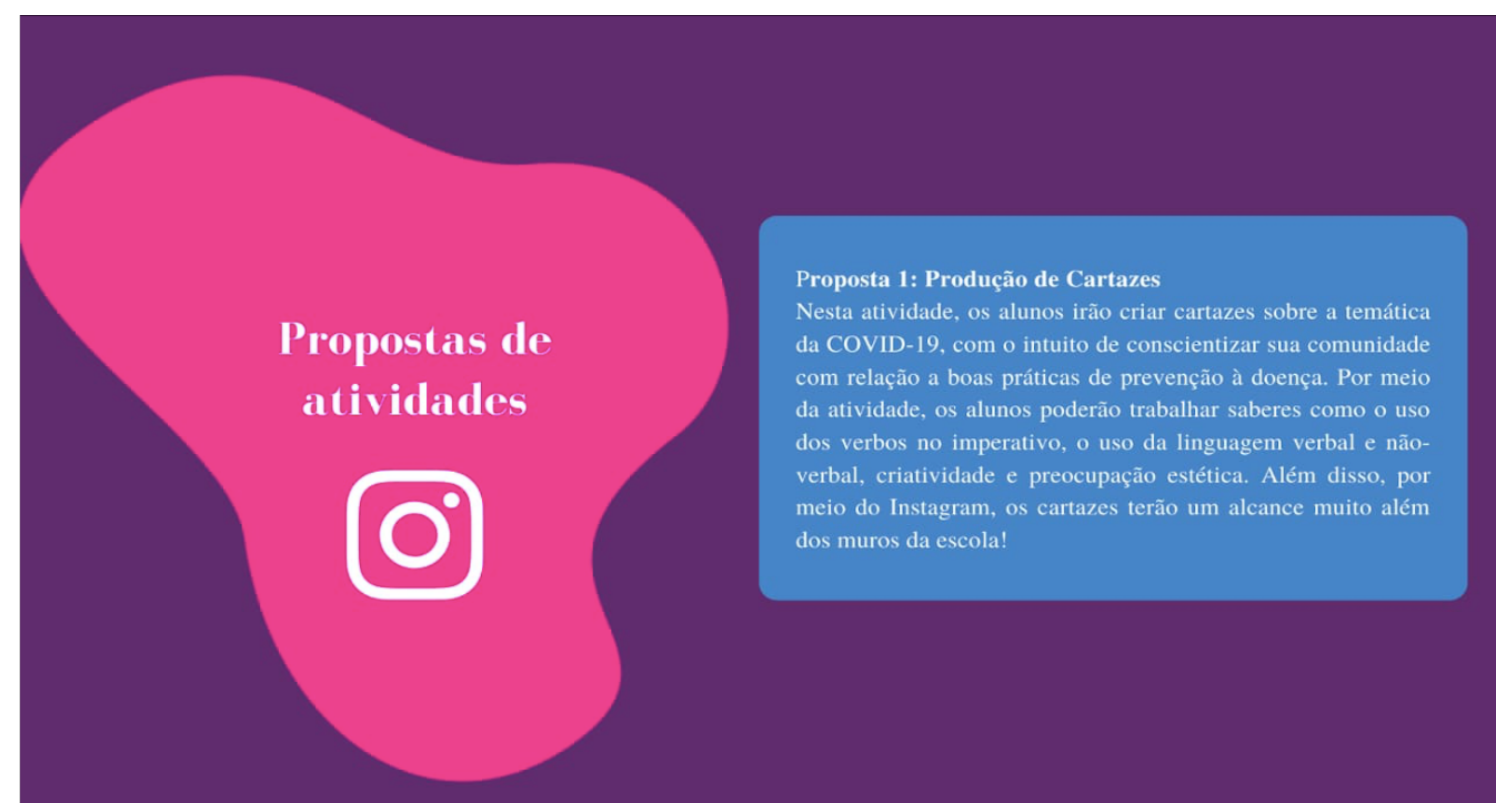

Figura 1

Na proposta 2 o aluno aprende sobre o gênero panfleto e também é estimulado a criar seu próprio panfleto obedecendo às regras sobre esse gênero textual.

Assim como na proposta 3 o aluno perceberá que o gênero textual folder é diferente do panfleto, sendo predominantemente usado para comunicar pautas de eventos ou informes publicitários.

Na proposta 4 os alunos serão levados a conhecer o conceito do gênero conto,

\footnotetext{
${ }^{1}$ Site para elaboração de animações: https: / / www . powt oon. com/
} 


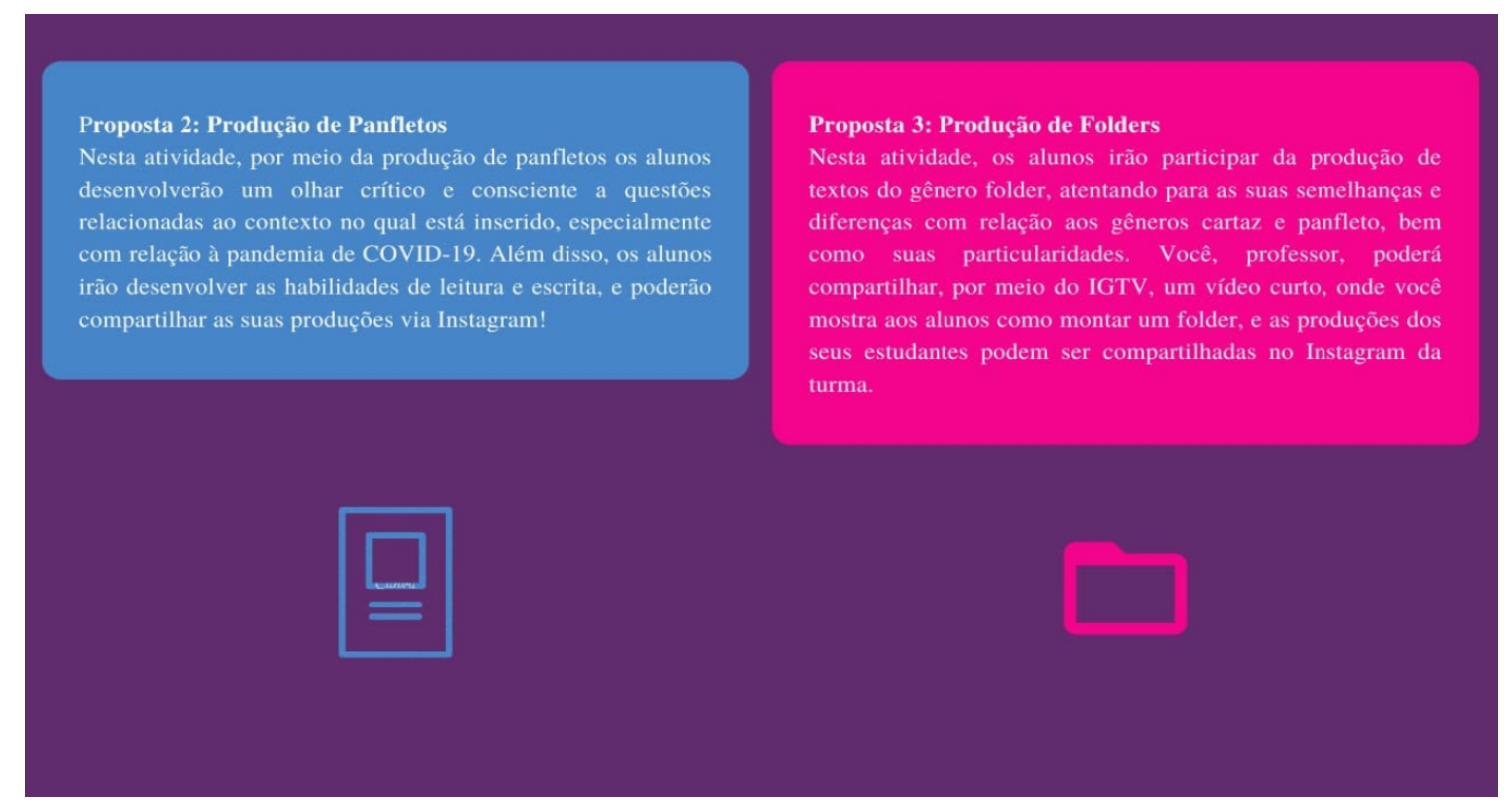

Figura 2

bem como as diversas possibilidades da escrita do gênero, sendo instigado a criar um conto utilizando as regras do RPG, sempre com foco no tema em questão.

Por fim, temos a proposta 5 que culminará com o gênero artigo de opinião, no qual o aluno fará uma síntese de tudo que aprendeu em relação aos tipos de textos diversos e também sobre a temática do Covid-19. Todas essas propostas de produção textual devem versar sobre a pandemia provocada pelo Covid-19.

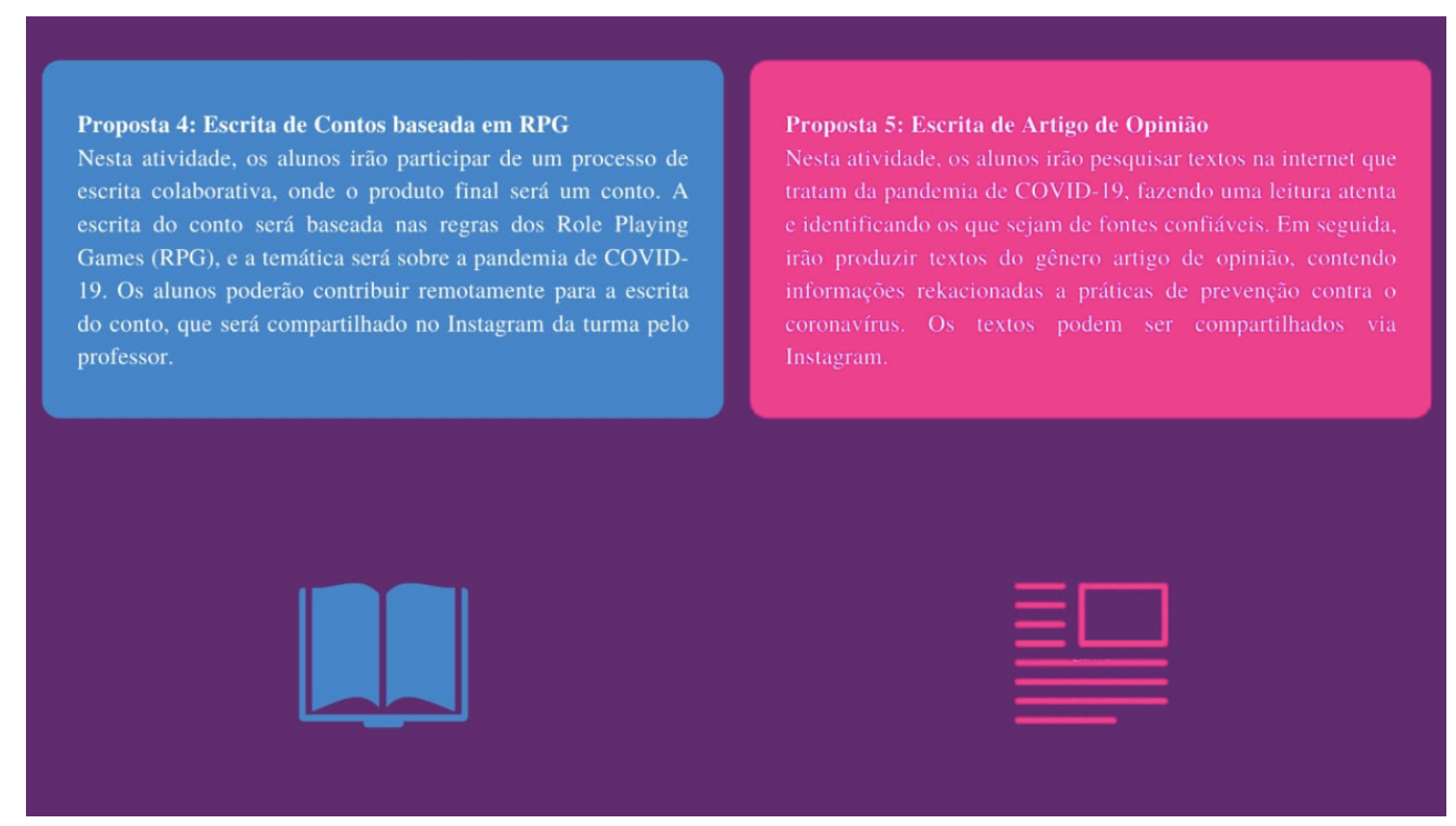

Figura 3

As figuras 4 e 5 demonstram o material produzido. Foi pensada uma maneira de reunir todo o material e para tal, utilizamos o Google Sites. Foi disponibilizado um tutorial básico de uso do Instagram para os professores que porventura não possuam domínio da ferramenta sintam-se encorajados a explorá-la. Foi criado um guia de Uso do Ins- 


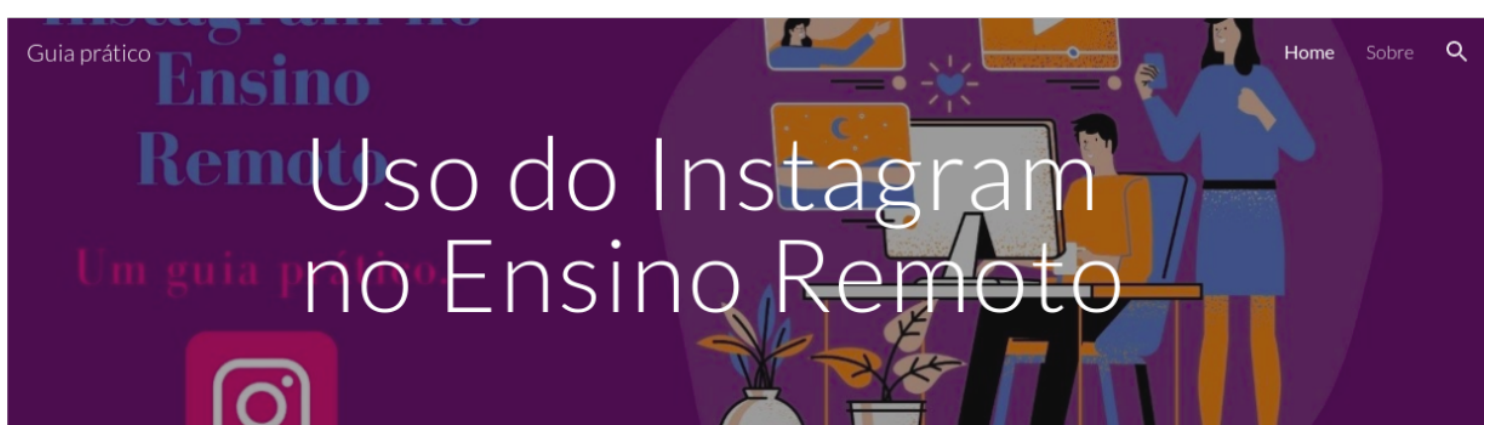

Figura 4

tagram no Ensino Remoto com o objetivo de possibilitar alternativas de trabalho para professores no atual contexto de distanciamento social. O guia contém as propostas de produções textuais resumidas e também o link de acesso para as propostas completas.

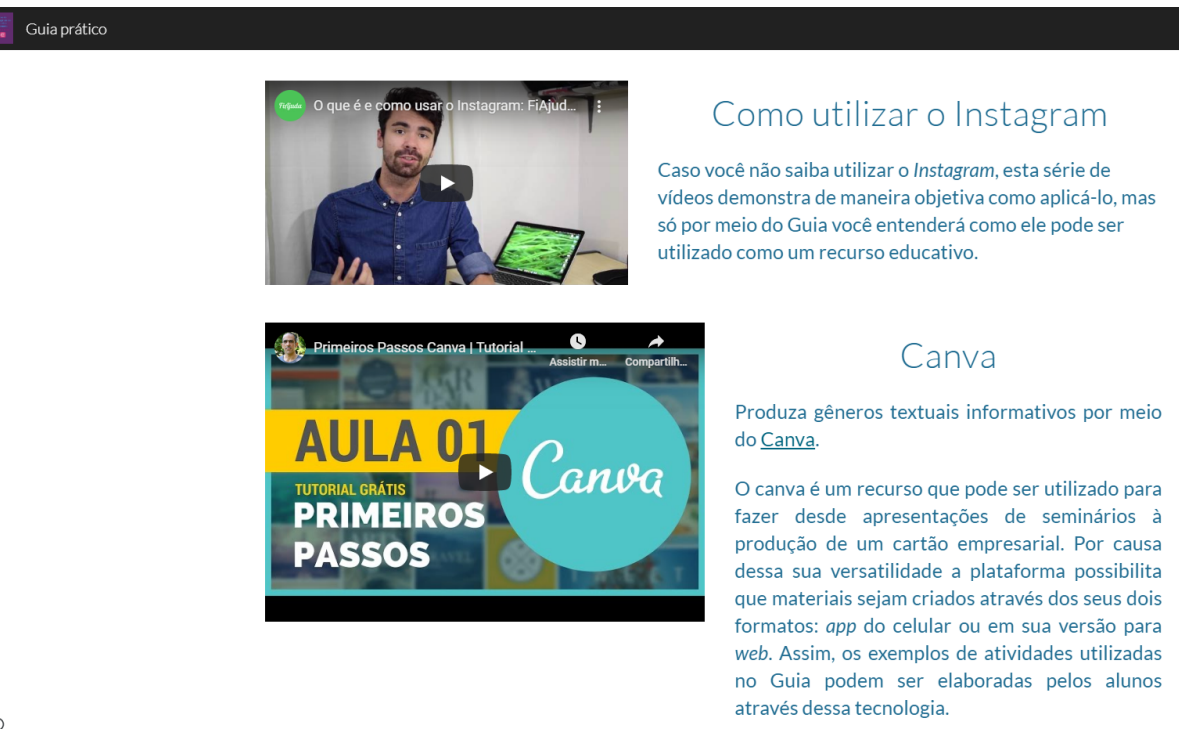

Figura 5

O tutorial sobre o Canva ajuda professores e alunos na produção dos gêneros sugeridos no guia, e, com a finalidade de recebermos uma devolutiva dos professores que tiverem acesso aos recursos elaborados, foi criado um documento no Google Forms para que eles possam dar feedback tendo em vista a melhoria da proposta. As atividades contidas no guia visam o desenvolvimento da habilidade de "Opinar e defender ponto de vista sobre tema polêmico relacionado a situações vivenciadas na escola e/ou na comunidade, utilizando registro formal e estrutura adequada à argumentação, considerando a situação comunicativa e o tema/assunto do texto" (habilidade EF35LP15), contida na BNCC.

\section{Considerações Finais}

No trabalho apresentado, pudemos observar a necessidade de inovação do fazer docente do professor, desta vez, em razão da pandemia ocasionada pelo Covid-19. Essa inovação, mais uma vez, recai sobre a necessidade da integração das tecnologias digitais no âmbito educacional. Mediante esse contexto, como manter os alunos motivados a aprender considerando o distanciamento social e as especificidades do ensino remoto? Tal questionamento evidencia a necessidade da escola repensar o seu ensino. Diante dessa realidade, 
pudemos observar que o momento atual tem sido um fator bastante propício para o engajamento das redes sociais nas situações de aprendizagem de estudantes da Educação Básica, considerando o fato de que esses alunos se utilizam dessas redes sociais para lazer/entretenimento. A partir disso, pensamos na criação de um guia para os professores conhecerem o espaço social que está configurado como o lugar de lazer dos discentes, buscando reconfigurá-lo também como um espaço de aprendizagem.

A proposta apresentada pode ser ampliada, possibilitando abordar outras áreas do Ensino Fundamental, como a disciplina de História a partir de conexões sobre o uso do Instagram como um meio de registro de fatos e opiniões de seus usuários. O professor, a partir desta rede social tão acessível pode estimular seus alunos a observarem as manifestações culturais encontradas, de modo a apresentar o ponto de vista discente em disciplinas como, Música ou Filosofia, com análises sobre o impacto causado pela nova forma de apreciar a arte musical por meio de lives, considerando as novas formas de interação entre artista e público, por exemplo.

Percebemos que as redes sociais estão disponíveis e que os alunos se sentem confortáveis em usá-las, mas que os docentes pouco sabem sobre seu uso. Recebemos feedback positivo, inclusive de professores que faziam uso do aplicativo mencionado, mas não utilizavam tal recurso para facilitar suas aulas. Recebemos também algumas sugestões, que nos motivaram a pensar a organização de um novo material referente ao uso das mídias digitais para crianças. O processo de concepção e elaboração do material nos mostrou que articular as ações educativas com o uso das redes sociais é algo que se mostra desafiador ao professor, no entanto, possível de ser exequível. Como trabalhos futuros, pretendemos organizar sequências didáticas voltadas para o uso seguro das TDIC, possibilitando ao professor abordar, de forma interdisciplinar, temáticas importantes para a realidade a qual vivemos.

\section{Referências}

Bakthin, M. (2011). Estética da criação verbal. Martins Fontes.

Bastos, T. B. M. C. and Boscarioli, C. (2020). Os professores do ensino básico e as tecnologias digitais: Uma reflexão emergente e necessária em tempos de pandemia. Library Catalog: horizontes.sbc.org.br.

Bates, T. (2016). Educar na era digital: design, ensino e aprendizagem. São Paulo: Artesanato Educacional, 7.

Brasil (2018). Base Nacional Comum Curricular. http://basenacionalcomum.mec.gov.br/.

CIEB (2020). CENTRO DE INOVAÇÃO PARA A EDUCAÇÃO BRASILEIRA: notas técnicas \#17: Estratégias de aprendizagem remota (EAR): Características e diferenciação da educação a distância (EAD). São Paulo: CIEB 2020. E-book em $p d f$.

Council, E. (2006). Recommendation of the european parliament and the council of 18 december 2006 on key competencies for lifelong learning. Brussels: Official Journal of the European Union, 30(12):2006.

Dellors, J. et al. (1999). Educação: um tesouro a descobrir: relatório para a unesco da comissão internacional sobre educação para o século xxi. Educação: um tesouro 
IX Congresso Brasileiro de Informática na Educação (CBIE 2020)

Anais do XXVI Workshop de Informática na Escola (WIE 2020)

a descobrir: relatório para a UNESCO da Comissão Internacional sobre Educação para o Século XXI.

DiSessa, A. A. (2001). Changing minds: Computers, learning, and literacy. Mit Press.

Faria, H. d. O. and Silva, L. d. O. (2012). Redes sociais na sala de aula: possibilidades. Integrando tecnologias no ensino de inglês nos anos finais do ensino fundamental. São Paulo: SM.

Garcia, D. N. d. M., Norte, M. B., and Messias, R. A. L. (2012). Tecnologia da informação e comunicação: Tics aplica à LE. São Paulo: Unesp - Universidade estadual Paulista, 2012. Disponível em: https://acervodigital.unesp.br/bitstream/123456789/45825/6/2ed_ing_m3d6.pdf.

Libâneo, J. C. (2002). Didática: velhos e novos temas.

Marcuschi, L. A. (2009). Produção textual, análise de gêneros e compreensão. Parábola Ed.

Mishra, P. and Koehler, M. J. (2006). Technological pedagogical content knowledge: A framework for teacher knowledge. Teachers college record, 108(6):1017-1054.

Morais, C., de Castro Filho, J. A., and Freire, R. S. (2018). Instagram e educação: a aprendizagem significativa de língua estrangeira em contextos não-formais de ensino. In Anais dos Workshops do Congresso Brasileiro de Informática na Educação, volume 7, page 906 .

Papert, S. M. (2007). A máquina das crianças: Repensando a escola na era da informática (edição revisada). Porto Alegre, RS: Editora Artmed.

Pereira, P. C., Borges, F. F., Batista, V. P. S., and Teles, L. F. (2019). Identificando práticas educacionais no instagram: uma revisão sistemática. Itinerarius Reflectionis, 15(2):01-19.

Ribeiro, R. M. (2009). A construção da argumentação oral em contexto de ensino. Cortez Editora.

Rolando, L. G. R., Luz, M. R. M. P., and Salvador, D. F. (2015). O conhecimento tecnológico pedagógico do conteúdo no contexto lusófono: uma revisão sistemática da literatura. Revista Brasileira de Informática na Educação, 23(03):174.

Santos, C. G. d. and Nunes, Netto, M. A. S. R. M. (2019). Guia de atividades desplugadas para o desenvolvimento do pensamento computacional: módulo de ensino 1. Porto Alegre: SBC, 2019. Disponível em: https://bit.ly/2CAQ8KC.

Shulman, L. (1987). Knowledge and teaching: Foundations of the new reform. Harvard educational review, 57(1):1-23.

World Health Organization et al. (2020). Who director-general's opening remarks at the media briefing on covid-19-11 march 2020. 